УДК 547.9:582.284.5

\title{
БИОАКТИВНЫЕ КОМПОНЕНТЫ ДРЕВЕСНОЙ ЗЕЛЕНИ ОБЛЕПИХИ HIPPOPHAE RHAMNOIDES L.
}

\author{
(C) Т.П. Кукина ${ }^{1 *}$, Д.Н. Щербаков ${ }^{2}$ К.В. Геньш ${ }^{2}$, Е.А. Тулышева ${ }^{2}$, О.И. Сальникова ${ }^{1}$, \\ А.Е. Гражжданников ${ }^{1,3}$, Е.А. Колосова ${ }^{4}$ \\ ${ }^{1}$ Новосибирский институт органической химии СО РАН им. Н.Н. Ворожцова, \\ пр. Акад. Лаврентьева, 9, Новосибирск, 630090 (Россия), \\ e-mail: kukina@nioch.ncs.ru \\ ${ }^{2}$ Алтайский государственный университет, пр. Ленина, 61, Барнаул, 656049 \\ (Россия) \\ ${ }^{3}$ Сибирский государственный университет геосистем и технологий, \\ ул. Плахотного, 10, Новосибирск, 630108 (Россия) \\ ${ }_{4}^{4}$ ФБУН ГНЦ ВБ «Вектор», р.п. Кольцово, Новосибирская область, 630559 \\ (Россия)
}

Изучен состав липофильных компонентов облиствленных побегов облепихи - крупнотоннажного отхода при производстве облепихового масла и при омолаживающих рубках культурных насаждений облепихи. В качестве экстрагента сырья использован гексан, обеспечивающий высокую степень извлечения липофильных компонентов и являющийся аналогом экстракционного бензина, применяющегося в пищевой и парфюмерной промышленности. Методами хроматомасс-спектрометрии и высокоэффективной жидкостной хроматографии исследован химический состав гексанового экстракта облиствленных побегов облепихи. Идентифицированы 67 нейтральных и 29 кислых компонентов, в том числе полипренолы, долихолы, тритерпеновые спирты и кислоты, стерины. Основной компонент стериновой фракции - $\beta$-ситостерин. Его содержание - $6,9 \%$ от массы экстракта, что значительно выше, чем в эфирных экстрактах листьев и жома плодов облепихи. В экстракте он обнаружен преимущественно в свободном виде. В кислой фракции наряду с мажорными алифатическими кислотами содержатся высокоактивные тритерпеновые кислоты (до 5\% массы экстракта). Во фракции полипренолов и долихолов (до 4,2\%) преобладают компоненты с длиной цепи 11 и 17 изопреновых единиц. Полученные результаты позволяют считать облиственные побеги облепихи перспективным источником биологически активных соединений.

Ключевые слова: Hippophae rhamnoides L., полипренолы, долихолы, стерины, тритерпеновые спирты, тритерепеновые кислоты, облиственные побеги.

\section{Введение}

Кукина Татьяна Петровна - старший научный сотрудник; доцент, e-mail: kukina@nioch.nsc.ru Щербаков Дмитрий Николаевич - кандидат биологических наук, доцент кафедры органической химии, e-mail: scherbakov_dn@vector.nsc.ru Геньш Константин Викторович - кандидат химических наук, преподаватель кафедры органической химии, e-mail: gensh632@gmail.com

Тулышева Екатерина Анатольевна - магистрант, e-mail: erizidakarma@mail.ru

Сальникова Ольга Иосифовна - ведущий инженер, e-mail:olga@nioch.nsc.ru

Гражданников Александр Евгеньевич - ведущий инженер, старший преподаватель кафедры техносферной безопасности, e-mail: agrash@nioch.nsc.ru Колосова Евгения Андреевна - аспирант, e-mail: kurchanovaea@gmail.com
В современном мире истощающихся природных запасов всё более остро встаёт вопрос интенсивного природопользования. Одним из таких направлений является рациональное использование растительного сырья.

Облепиха Hippophae rhamnoides издавна применяется в народной медицине в качестве лекарственного растения. При упоминании растения рода Облепиха возникают ассоциации с плодами и облепиховым маслом. А ведь у этого растения полезными свойствами обладают еще и вегетативные части растения: листья, корни, побеги. В листьях содержится до 10\% танина, более 300 мг\% витамина С,

\footnotetext{
* Автор, с которым следует вести переписку.
} 
до 1\% флавоноидов. В них также найден серотонин, особенно много его в коре ветвей [1]. Химический состав плодов и листьев облепихи широко изучен [2-7]. В этих частях растения обнаружено более 200 биологически активных соединений: флавоноиды, гликозиды, алифатические кислоты, углеводороды, альдегиды, спирты, углеводы, каротиноиды, витамины, полипренолы, долихолы, стерины, нейтральные и кислые тритерпеноиды. Литературные данные [5, 8] указывают, что наибольший вклад в активность липофильных препаратов (таких как облепиховое масло) вносят стерины. В эфирных экстрактах жома плодов и листьев облепихи содержание $\beta$-ситостерина достаточно высоко: 1 и 3\% соответственно [2, 5]. При этом он практически не сопровождается другими стеринами. Облепиха также богата тритерпеновыми спиртами с аналогичными стеринам видами активности $[2,3,5]$.

В то же время состав облиственных побегов этого растения изучен недостаточно, хотя именно они являются крупнотоннажным отходом при производстве облепихового масла и омолаживающих рубках культурных насаждений облепихи. Поэтому цель работы - изучение химического состава гексанового экстракта облиствленных побегов облепихи.

\section{Экспериментальная часть}

Измельчение сырья проводилось на электрической мельнице. Использован ротационный испаритель Büchi, Швейцария. Тонкослойная хроматография проведена на пластинках Sorbfil и Армсорб в системе гексан - метил-трет-бутиловый эфир (анализ фракции малополярных соединений $6: 1$, остальные фракции $1: 1$ соответственно). Проявление хроматограмм проводили опрыскиванием пластинок смесью ванилин - серная кислота - спирт в соотношении $1: 10: 90$ с последующим подогревом пластинки. Очистка целевых соединений осуществлялась с помощью колоночной хроматографии на силикагеле фирмы SigmaAldrich (Merck Grade 7734) 70-230 mesh. В качестве элюента применен гексан с повышающимся от 1 до 50\% содержанием диэтилового эфира. Хроматомасс-спектры записаны на приборе Hewlett Packard G 1800 А, состоящем из газового хроматографа НP 5890 серии II и масс-селективного детектора НР 5971. Колонка 30 м $\times 0,25$ мм $\times 0,25$ мкм с сорбентом HP-5MS (5\% - дифенил, 95\% - диметилсилоксан). Газ-носитель гелий (1 мл/мин). Температура колонки: 2 мин при $50{ }^{\circ} \mathrm{C}$, далее повышение температуры со скоростью $4{ }^{\circ} \mathrm{C} /$ мин до $300{ }^{\circ} \mathrm{C}, 30$ мин - при $300{ }^{\circ} \mathrm{C}$. Температура испарителя $-280{ }^{\circ} \mathrm{C}$, источника ионов $-170{ }^{\circ} \mathrm{C}$. В качестве аналитического прибора для ВЭЖХ использован жидкостный хроматограф Милихром-2 с УФдетекцией при длине волны 210 нм; колонка 7,0×0,2 см, заполненная сорбентом ProntoSil 120-5-С18; элюент - смесь метанола с ацетоном (1 : 3 по объему).

В качестве экстрагента нами выбран малотоксичный растворитель гексан, обеспечивающий высокую степень извлечения липофильных компонентов растительного сырья таких, как сложные эфиры, включая жиры, углеводороды, свободные алифатические кислоты, полипренолы, долихолы, нейтральные тритерпеноиды и стерины в свободном и связанном виде. Использование гексана перспективно, так как позволяет удлинить технологическую цепочку за счет использования более полярных растворителей с целью исчерпывающего извлечения биологически активных компонентов и комплексной утилизации крупнотоннажного сырья.

Экстракция проводилась в аппарате Сокслета в течение 7 ч. Выход экстракта составил 4\%.

Для облегчения анализа гексановый экстракт облепихи сначала разделяли на кислые и нейтральные компоненты (рис.) $[3,5,9,10]$. Свободные кислоты выделялись из суммарного экстракта щелочной экстракцией $2 \%$ водным раствором гидроксида натрия. Нейтральная часть при этом являлась суммой алифатических углеводородов и алифатических и тритерпеновых спиртов в свободном виде и в виде сложных эфиров с алифатическими кислотами. Также была необходима дополнительная стадия фракционирования омыление: с помощью щелочного гидролиза были получены фракции суммарных кислот и неомыляемых веществ (рис.).

\section{Обсуждение результатов}

Неомыляемые вещества представляют собой сумму алифатических углеводородов, алифатических и тритерпеновых спиртов, полиизопреноидов (полипренолы и долихолы включительно), а также стеринов и тритерпеноидов (табл. 1). 


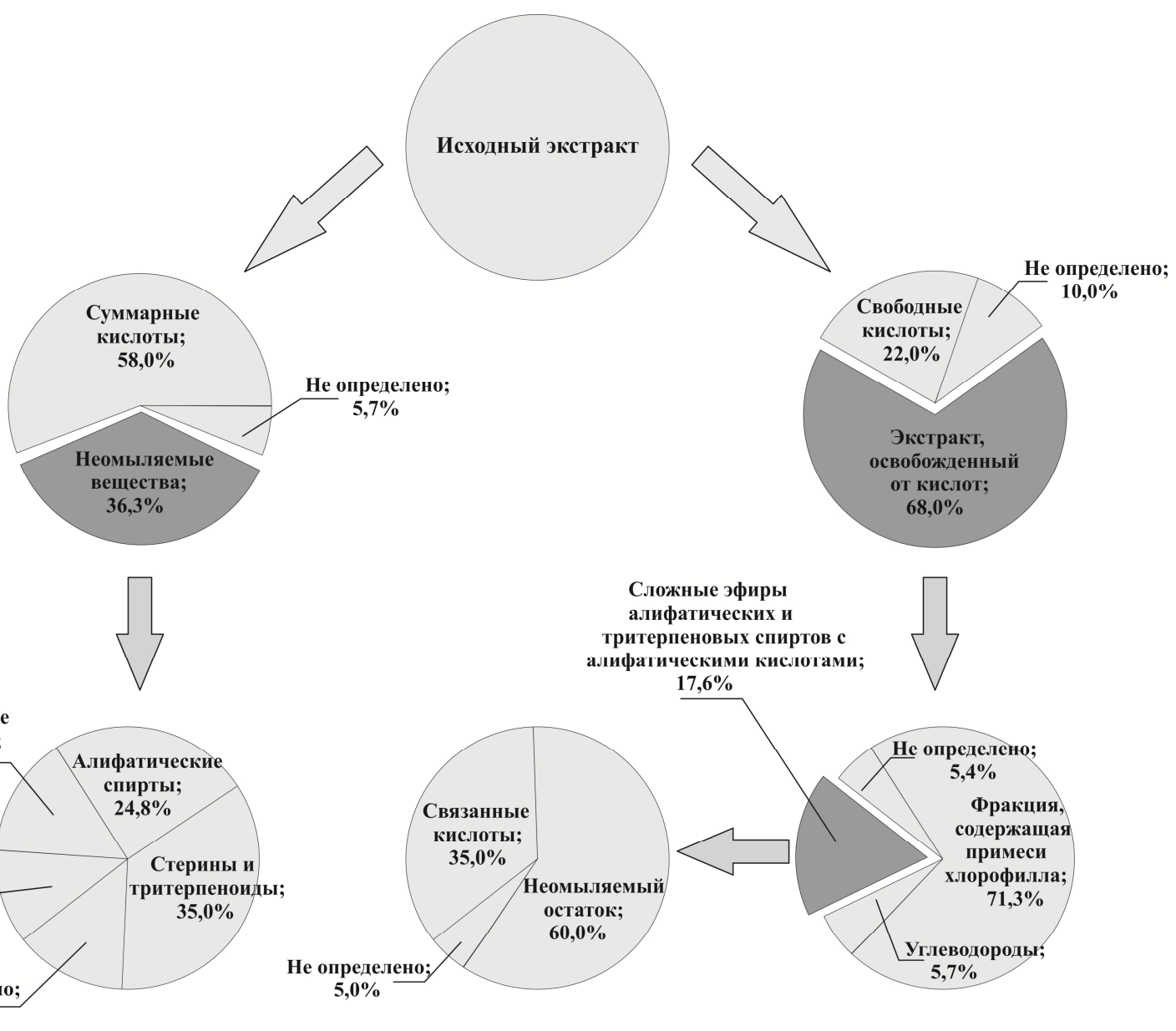

Схема анализа экстракта облиственных побегов облепихи

Таблица 1. Соотношение групп соединений в неомыляемом остатке (НО)

\begin{tabular}{l|c|c}
\hline \multicolumn{1}{c|}{ Группа соединений } & Процент в НО & Процент в экстракте \\
\hline Алифатические углеводороды & 14,8 & 9,4 \\
Алифатические спирты & 24,8 & 4,2 \\
Полипренолы и долихолы & 11,5 & 12,7 \\
Стерины и тритерпеноиды & 35,0 & \\
\hline
\end{tabular}

Фракции неомыляемого остатка экстракта были исследованы методами хроматомасс-спектрометрии и высокоэффективной жидкостной хроматографии.

Во фракции алифатических углеводородов было идентифицировано 26 соединений (табл. 2). Преобладают парафины с нечетным числом атомов. Содержание чётных углеводородов значительно ниже. Основные компоненты этой фракции - нонакозан, гентриаконтан и гептакозан - составляют в сумме более $85 \%$ этой группы соединений.

Основные компоненты фракции алифатических спиртов - фитол, октадеканол и тетракозанол, они составляют более 75\% этой группы соединений. Известно [5], что фитол присутствует в листьях облепихи не только как составляющая хлорофилла, но и в виде эфиров с алифатическими кислотами. Всего идентифицировано 8 соединений (табл. 3).

Во фракции полиизопреноидов идентифицировано 17 соединений. Здесь преобладают компоненты с длиной цепи 11 и 17 изопреновых единиц (табл. 4). Высокий процент долихолов в полиизопреноидной фракции увеличивают перспективность липофильного концентрата облиственных побегов облепихи в качестве биоактивной субстанции.

Основной компонент терпеновой фракции - $\beta$-ситостерин (табл. 5), а также трудноразделимая смесь $\alpha$-амирина, лупеола и циклоартенола, кроме того, были обнаружены фукостерин и компоненты, ранее найденные в листьях облепихи [2-5]. 
Соотношение алифатических и тритерпеновых кислот во фракциях гексанового экстракта облиственных побегов облепихи сведено в таблицу 6. Всего идентифицировано 29 кислых компонентов.

Во всех трех фракциях преобладают пальмитиновая, линолевая, линоленовая, бегеновая кислоты, характерные для листьев облепихи. Во фракциях свободных и суммарных кислот обнаружены олеаноловая и урсоловая кислоты. Во фракции кислот, выделенных из сложных эфиров, присутствуют только алифатические кислоты.

Таблица 2. Распределение компонентов во фракции алифатических углеводородов (процент от массы фракции)

\begin{tabular}{l|c|l|c}
\hline \multicolumn{1}{c|}{ Компонент } & \multicolumn{1}{|c}{ Компонент } & Процент \\
\hline Тридекан & 0,03 & Гексакозан & 5,16 \\
Тетрадекан & 0,10 & Гептакозан & 3,18 \\
Пентадекан & 0,10 & Октакозан & 1,27 \\
Гексадекан & 0,15 & Сквален & 59,66 \\
Гептадекан & 0,12 & Нонакозан & 4,42 \\
Октадекан & 0,14 & Триаконтан & 20,00 \\
Нонадекан & 0,13 & Гентриаконтан & 0,81 \\
Эйкозан & 0,14 & Дотриаконтан & 0,70 \\
Генэйкозан & 0,14 & Тритриаконтан & 0,22 \\
Докозан & 0,15 & Тетратриаконтан & 0,17 \\
Трикозан & 0,39 & Пентатриаконтан & 0,14 \\
Тетракозан & 0,31 & Гексатриаконтан & 0,10 \\
Пентакозан & 1,33 & Гептатриаконтан \\
\hline
\end{tabular}

Таблица 3. Распределение компонентов во фракции алифатических спиртов (процент от массы фракции)

\begin{tabular}{l|c|l|c}
\hline \multicolumn{1}{c|}{ Компонент } & Процент & \multicolumn{1}{c}{ Компонент } & Процент \\
\hline Гексадеканол & 0,1 & Докозанол & 0,5 \\
Фитол & 27,1 & Трикозанол & 25,0 \\
Октадеканол & 23,1 & Тетракозанол & 2,9 \\
Эйкозанол & 9,9 & Гексакозанол & \\
\hline
\end{tabular}

Таблица 4. Распределение компонентов в полиизопренодной фракции (процент от массы фракции)

\begin{tabular}{|c|c|c|c|}
\hline Компонент & Процент & Компонент & Процент \\
\hline ПП-8* & 2,97 & ПП-15 & 5,10 \\
\hline ПП-9 & 3,42 & Д-15 & 1,00 \\
\hline ПП-10 & 6,32 & ПП-16 & 9,56 \\
\hline ПП-11 & 30,18 & Д-16 & 1,21 \\
\hline ПП-12 & 10,75 & ПП-17 & 16,00 \\
\hline ПП-13 & 4,09 & Д-17 & 3,49 \\
\hline Д-13** & 0,73 & ПП-18 & 6,82 \\
\hline ПП-14 & 1,64 & Д-18 & 1,62 \\
\hline Д-14 & 0,27 & & \\
\hline
\end{tabular}

Таблица 5. Распределение компонентов во фракции тритерпеноидов и стеринов (процент от массы фракции)

\begin{tabular}{|c|c|c|c|}
\hline Компонент & Процент & Компонент & Процент \\
\hline Стигмастанол & 0,80 & Олеаноловый альдегид & 0,82 \\
\hline$\beta$-Ситостерин & 54,00 & Урсоловый альдегид & 1,16 \\
\hline Фукостерин & 1,12 & Уваол & 0,27 \\
\hline$\beta$-Амирин & 4,25 & Эритродиол & 0,50 \\
\hline$\alpha$-Амирин+лупеол+циклоартенол & 34,37 & 28-нор-олеан-12,18(17)-диен-3-ол & 0,49 \\
\hline 24-метиленциклоартанол & 1,30 & 28-нор-урс-12,18(17)-диен-3ß-ол & 0,65 \\
\hline Цитростадиенол & 0,18 & Обтузифолиол & 0,10 \\
\hline
\end{tabular}

Таблица 6. Распределение компонентов во фракциях кислот (процент от массы фракции)

\begin{tabular}{l|c|c|c}
\hline \multicolumn{1}{c|}{ Кислота /Образец } & Суммарные кислоты & Свободные кислоты & Кислоты сложноэфирной фракции \\
\hline \multicolumn{1}{c|}{$l$} & 2 & 3 & 4 \\
\hline Бензойная & 0,76 & $-^{*}$ & 0,11 \\
Лауриновая $\mathrm{C}_{12}$ & 0,96 & следы & 1,18 \\
Миристиновая $\mathrm{C}_{14}$ & 4,24 & 1,71 & 5,64 \\
\hline
\end{tabular}


Окончание таблицы 6

\begin{tabular}{|c|c|c|c|}
\hline 1 & 2 & 3 & 4 \\
\hline Пентадекановая $\mathrm{C}_{15}$ & 1,20 & 1,39 & 2,13 \\
\hline Пентадеценовая $\mathrm{C}_{15: 1}$ & 0,37 & - & 0,33 \\
\hline Пальмитиновая $\mathrm{C}_{16}$ & 16,71 & 19,16 & 24,19 \\
\hline Гексадекандиовая $\mathrm{C}_{16}$ & 0,83 & - & - \\
\hline Пальмитолеиновая $\mathrm{C}_{16: 1}$ & 1,02 & 1,15 & 0,93 \\
\hline Пальмитолинолевая $\mathrm{C}_{16: 2}$ & следы & - & 0,25 \\
\hline Пальмитолиноленовая $\mathrm{C}_{16: 3}$ & следы & 0,73 & 1,18 \\
\hline Маргариновая $\mathrm{C}_{17}$ & 0,51 & 0,48 & 0,55 \\
\hline Гептадекантриеновая & - & - & 0,49 \\
\hline Стеариновая $\mathrm{C}_{18}$ & 2,14 & 2,41 & 2,45 \\
\hline Олеиновая $\mathrm{C}_{18: 1}$ & 1,12 & 2,36 & 0,71 \\
\hline Линолевая $\mathrm{C}_{18: 2}$ & 16,86 & 9,50 & 8,64 \\
\hline Линоленовая $\mathrm{C}_{18: 3}$ & 10,22 & 16,66 & 15,83 \\
\hline Арахиновая $\mathrm{C}_{20}$ & 5,28 & 3,08 & 9,01 \\
\hline Генэйкозановая $\mathrm{C}_{21}$ & 0,12 & 0,57 & 1,25 \\
\hline Бегеновая $\mathrm{C}_{22}$ & 16,23 & 7,54 & 19,51 \\
\hline Трикозановая $\mathrm{C}_{23}$ & 1,73 & 1,14 & 1,12 \\
\hline Тетракозановая $\mathrm{C}_{24}$ & 3,19 & 1,99 & 3,11 \\
\hline Пентакозановая $\mathrm{C}_{25}$ & 0,43 & - & 0,18 \\
\hline Гексакозановая $\mathrm{C}_{26}$ & 0,32 & 0,39 & 0,22 \\
\hline Октакозановая $\mathrm{C}_{28}$ & 0,49 & 0,52 & следы \\
\hline Нонакозановая $\mathrm{C}_{29}$ & 0,18 & - & - \\
\hline Триаконтановая $\mathrm{C}_{30}$ & 0,31 & 1,42 & - \\
\hline Дотриаконтановая $\mathrm{C}_{32}$ & 0,17 & - & - \\
\hline Олеаноловая & 4,84 & 9,01 & - \\
\hline Урсоловая & 6,72 & 11,95 & - \\
\hline
\end{tabular}

\section{Выводы}

1. Методами хроматомасс-спектрометрии и высокоэффективной жидкостной хроматографии исследован химический состав гексанового экстракта облиственных побегов облепихи.

2. Идентифицированы 67 нейтральных и 29 кислых компонентов, в том числе полипренолы, долихолы, тритерпеновые спирты и кислоты, стерины.

3. Основной компонент стериновой фракции - $\beta$-ситостерин. Его содержание $-6,9 \%$ от массы экстракта, что значительно выше, чем в эфирных экстрактах листьев и жома плодов облепихи. В экстракте он обнаружен преимущественно в свободном виде. (Соотношение свободный : связанный $30: 1$ ).

4. В кислой фракции наряду с мажорными алифатическими кислотами содержатся высокоактивные тритерпеновые кислоты (до 5\% массы экстракта).

5. Во фракции полипренолов и долихолов (до 4,2\%) преобладают компоненты с длиной цепи 11 и 17 изопреновых единиц. Высокий процент долихолов в полиизопреноидной фракции увеличивают перспективность липофильного концентрата облиственных побегов облепихи в качестве биоактивной субстанции.

6. Полученные результаты позволяют считать облиственные побеги облепихи перспективным растительным сырьем.

\section{Список литературы}

1. Патент № 2533818 (РФ). Способ получения порошковых препаратов, содержащих серотонин, из неплодовых частей облепихи / Д.А. Рычков, Е.В. Болдырева / 2014.

2. Кошелев Ю.А., Агеева Л.Д. Облепиха. Бийск, 2004. 320 с.

3. Salenko V.L., Kukina T.P., Karamyshev V.N., et al. Chemical study of Hippophae rhamnoides. Main components of the neutral fraction of saponification products of extracts from sea buckthorn leaves // Chemistry of natural Compounds. 1985. Vol. 21. Рp. 481-485.

4. Кукина Т.П., Деменкова Л.И., Ралдугин В.А., Максимов Б.И., Чижов О.С., Веселовский В.В. Полипренолы и долихолы листьев облепихи // Сибирский химический журнал. 1991. Вып. 6. С. 89-93.

5. Кукина Т.П. Биологически активные изопреноиды листьев облепихи : автореф. дис. ... канд. хим. наук. Новосибирск, 1992. 26 с. 
6. Кукина Т.П., Ралдугин В.А. Маслиновая и гидроксиурсоловая кислоты листьев облепихи // Сибирский химический журнал. 1992. Вып. 2. С. 92-93

7. Мельников О.М., Верещагин А.Л., Кошелев Ю.А. Изучение биологически активных компонентов почек и листьев мужских растений облепихи // Химия растительного сырья. 2010. №2. С. 113-116.

8. Лечамо В., Лобачева И.И. О стандартизации облепихового масла // Химия растительного сырья. 1997. №1. C. $22-25$.

9. Кукина Т.П., Баяндина И.И., Покровский Л.М. Неполярные компоненты экстрактов зверобоя продырявленного // Химия растительного сырья. 2007. №3. С. 39-45.

10. Kukina T.P., Frolova T.S., Salnikova O.I. Neutral Constituents of Chamaenerion angustifolium Leaves // Chemistry of Natural Compounds. 2014. Vol. 50. N2. Pp. 233-236.

Поступило в редакиию 2 февраля 2016 г.

После переработки 6 февраля 2016 г.

Kukina T.P. ${ }^{l}{ }^{*}$, Shcherbakov D.N. ${ }^{2}$, Gensh K.V. ${ }^{2}$, Tulysheva E.A. ${ }^{2}$, Salnikova O.I. ${ }^{l}$, Grazhdannikov A.E. ${ }^{1,3}$, Kolosova E.A. ${ }^{4}$ BIOACTIVE CONSTITUENTS FROM SEA BUCKTHORN HIPPOPHAE RHAMNOIDES L. TREE GREEN

${ }^{I}$ Novosibirsk Institute of Organic Chemistry SB RAS. N.N. Vorozhtsova, pr. Akad. Lavrenteva, 9, Novosibirsk, 630090

(Russia),e-mailkukina@nioch.ncs.ru;

${ }^{2}$ Altay State University, pr. Lenina, 61, Barnaul, 656049 (Russia)

${ }^{3}$ Siberian State University of geosystems and Technology, ul. Plakhotnogo, 10, Novosibirsk, 630108 (Russia)

${ }^{4}$ FBUN SSC "Vector", Koltsovo, Novosibirsk Region, 630559 (Russia)

The data about twigs with leaves constituents of sea buckthorn are insufficient in spite of the fact that it is the large waste product of sea buckthorn oil production and tender cutting. Twigs with leaves (so called tree green) were object of our investigation. We used hexane as extragent. Hexane is an analog of commercial solvent and guarantees exhaustive extraction of lipophilic constituents. The composition of this extract was investigated by GC/MS and HPLC. As a result 67 neutral and 29 acid constituents such as aliphatic and triterpenic acids and alcohols, sterols, aldehydes, polyprenols, dolichols, hydrocarbons were identified. The main component of the sterol fraction - $\beta$-sitosterol. Its content $-6,9 \%$ by weight of the extract, which is significantly higher than the ether extracts of sea buckthorn leaves and fruit pulp. In the extract it is found predominantly in the free form. The acidic fraction along with main aliphatic acids contain minor highly triterpene acids (up to 5\% weight of the extract). The main component of dolichol and polyprenol fraction (to 4,2\%) is a compaunds with 11 and 17 isoprene units. These results suggest leafy shoots of sea buckthorn promising source of biologically active compounds.

Keywords: Hippophae rhamnoides L., polyprenols, dolichols, sterols, triterpene alcohols, triterepenovye acid, leafy shoots.

\section{References}

1. Patent 2533818 (RU). 2014. (in Russ.).

2. Koshelev Ju.A., Ageeva L.D. Oblepiha. [Sea buckthorn]. Bijsk, 2004, 320 p. (in Russ.).

3. Salenko V.L., Kukina T.P., Karamyshev V.N., et al. Chemistry of natural Compounds, 1985, vol. 21, pp. 481-485.

4. Kukina T.P., Demenkova L.I., Raldugin V.A., Maksimov B.I., Chizhov O.S., Veselovskij V.V. Sibirskij himicheskij zhurnal, 1991, no. 6, pp. 89-93. (in Russ.).

5. Kukina T.P. Biologicheski aktivnye izoprenoidy list'ev oblepihi. Avtoref. Dis. ...kand. him. nauk. [Biologically active isoprenoids buckthorn leaves. Abstract Dis. ... Candidate of chemical sciences.]. Novosibirsk, 1992, 26 p. (in Russ.).

6. Kukina T.P., Raldugin V.A. Sibirskij himicheskij zhurnal, 1992, no. 2, pp. 92-93. (in Russ.).

7. Mel'nikov O.M., Vereshhagin Koshelev Ju.A. Himija rastitel'nogo syr'ja, 2010, no. 2, pp. 113-116. (in Russ.).

8. Lechamo V. Lobacheva I.I. Khimija rastitel'nogo syr'ja, 1997, no. 1, pp. 22-25. (in Russ.).

9. Kukina T.P., Bajandina I.I., Pokrovskij L.M. Khimija rastitel'nogo syr'ja, 2007, no. 3, pp. 39-45. (in Russ.).

10. Kukina T.P., Frolova T.S., Salnikova O.I. Chemistry of Natural Compounds, 2014, vol. 50, no. 2, pp. $233-236$.

Received February 2, 2016

Revised February 6, 2016

\footnotetext{
* Corresponding author.
} 